\title{
Köpeklerde östrus ve uygun tohumlama zamanının saptanmasında vaginal sekresyon glukoz içeriğinin kriter olarak değerlendirilmesi
}

\author{
Rauf TÜNAY', Necmettin TEKIN ${ }^{2}$, Ali DAŞKIN²

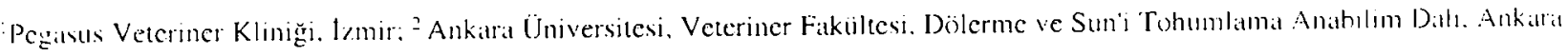

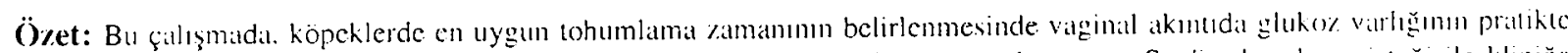

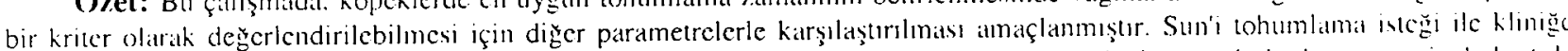

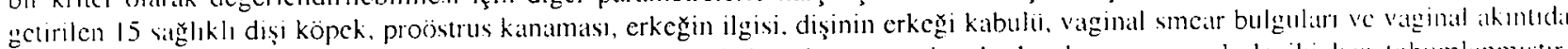

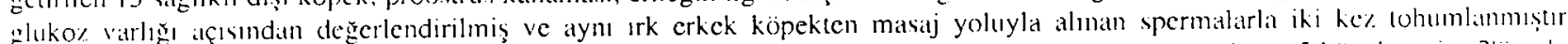
Negallif glukuz test sonucu gösteren 10 köpekten 7 gebelik elde edilmiştir. Pozitif gélukoz. test sonucu alman 5 köpekten ise 3 'ij gęebo

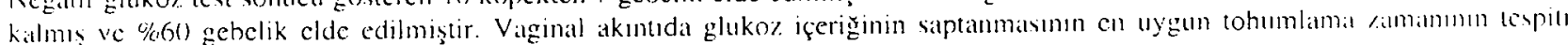

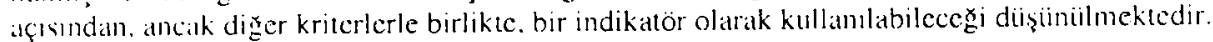

Anahtar kelimeler: Gluko\%. köpek. Lohumlama zamamı, vaginal akuntı. vaginal smear

\section{Determination of glucose in vaginal secretion for estrus and optimum time for insemination in dogs}

Summary: The aim of this study is to compare the glucose found in the vaginal discharge with the other partumcicis, 10 value it at at praticable criterion in determining the most suitable period for the inseminaton of dogs. Fiftecn healthy dogs which request artificial inscmination were valued according to the vaginal blecding. the interest of the male, acceptance of the fomale, lalginal smatr and glucose found in vaginal discharge: and they were inseminaled ewo times with sperms of a male silme breed. which wils

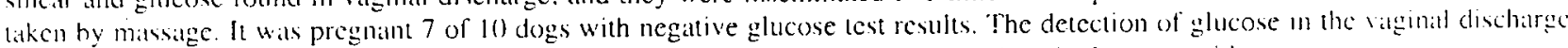
catn be valuable indicator of the time for breeding using other clinical, behavioral and viginal smear evidence.

Key words: Dog. glucose, time of insemination. vaginal smear, vaginal secretion

\section{Giriş}

Óstrusun. ovulasyonun ve en uygun tohumlama 7.amanumn belitlenmesi, köpekte normal reprodiiksiyonun stirdürüilmesi için önemlidir. Cünküi, dişi köpeklerdeki uygulamalarda olası infertilitenin en önemli nedenlerinden biri. uygun olmayan çiftleşme ve tohumlama zamanlandır. Ovulasyon zanıanıun saptanması, çiftleşme ya da örellikle sun'i tohumlama için en uygun zamanının belirlenmesinde ve dolayısıyla döl veriminde çok önemIidir. Bu amaçla. köpeklerin östrus siklusunun hangi cvresinde olduğunu ve en uygun tohumlama zamanın belirlemek için değgişik yöntemler kullanılmaktadır. Erkeği kabul. vulva akıntısı ya da vaginal smear gibi kriterler kullanılmakla birlikıc hunların hiçbiri tek başına tam bir değerlendirme kriteri olamamakladır $(3,14)$.

Köpeklerde östrus suiresi, 4-12 güin arası değişnekle birliktc ortalama 9 gündür, ancak 27 veya 30 günlük östrus sürcleri de lespit edilmiştir. Belirtilen süre erkck köpeğin kabul edilmesinin ilk ve son günleriyle sınırlıdır. Dişi genellikle daha önce artmuş olan östrojen düzeyi düşmeye başlayıncaya kadar crkeği kabul eder. Proöstrusun sonları ve östrusun başlanglcunda östrojen düzeyi düşerken, ovaryumlar tarafundan önemli miktarda progestcron üretilir. Proöstrusun son günlerinde serum pro- gesteron düzeyindeki artı̧ ve serum östrojen konsantrasyonlarındaki azalma ikj ana olguyu birlikle uyanm Bunlardan birincisi. dişinin çiftleşmeye pasif olarak di. renç gösterirken aktif olarak çiflleşmek istemesi ş̣klindeki davranış degişimleri. ikincisi ise hipolizden ovulasyonu uyaran follikül stimule edici homon (FSH) ve özelliklc luteinize edici hormon (LH) un salmmasidn $(6,12,15)$.

Cinsel aktivitenin diğer deyimle ovariyel aktivitenin olduğu süreçte genital orgeanlarda oluşan kimi fizyolojik değişiklikler ve kimyasal bileşimlerinde larklılaşmalaı gözlenmekıc, proöstrus ve östrus olarak adlandurlan bu sürelerin birlikte ortalana 19.4 giin (11-35 giin arissi) vo vulval akıntının ortalama 20.5 gïn (4-37 güu) olduğu bildirilmektedir $(7,13)$.

Özellikle östrus sürecine giren dişi köpek erkeğe il gilidir ve onu yanına çekmek ister. Arka tarafim erkeğe doğru döndürüp. sırtın alçaltıp pelvik brilgecyi yuikselterek perianal bölgeyi gösterir ve kuyruğunu yana alarak vulvayı açar. Perincum bölgesi genişlemiş. vulva ödenıi belirgin hale gelmiş, vaginal akıntı kımızıdan. berrak veya sarıya döniişmiiştiir. Periyodun sonuna doğru bu ödem azahr ve östrustan 1-2 hafta somra normal haline 
ciöncr. Vaginal mukoza hiperplastik ve soluk pembedir. Kıvrimlar belirgin, serviks kısmen açıtır (4,5,7.13).

Dişi köpeklerde vaginal akıntunın glukoz konsilltrasyonu, östrus siklusu boyunca deģişkenlik göscomcktedir. Vaginal akıntıda glukoz varlığı, glukolest çuhuğunun vagina içerisinde bir dakika bekletilmesiyle lespil edilebilir. Glukotesı çubuğu bandının kenarları vaginal akıntıda glukoz varlığmda yeşil renk almaktadır. Eğer glukoz yoksa salrı renkte kalmaktadır. Ancak, muayene orlamunda kan bulunması değerlendirmeyi yanlış yonlendirebilmektedir. Vaginal akıntıdaki gluko\% konsantrasyonumun optinal tohumlama zamanunn sapLanmasinda ve dolayess ile optimum fertilitonin clde edilmesinde değgerli bir indikatör olduğ (17) kabul edilmekte ise de kimi araşuncular (8.16). bu kriterin tek başna yetcrli olmadığmı ve bu tekniğin bilimsel olarak pek fazla deslekklenmediğgini ifade elmekledir

Kimi araşırmalara göre, muayene ve değerlendirmelerde negatil gluko\% reaksiyonu vaginada keratinize huicrelerin maksimum olduğg döncme tekabül etmektedir (2). Gluko\% testinin negatif olduğu dönende yapılan çiftleștime ya dil tohumlamalardan en iyi fertilite oranı elde edildiği kaydedilmekledir. Vaginal akıntıda glukoz içeriğgine değişik siire ve miklarlarda rastlanmakla birlikıe çoğunlukla ikinci negalil reaksiyon oluşmadian çiftleşme meydana gelmemektedir. Yapılan bir çalışmada bu zamandan önce yap̧lan çifileştirmelerde 23 köpekten sadece 2 lanesinde gebelik gerçekleşmiştir (17).

Köpeklerde vaginal smear muayeneleri, klinik östrus beldekleri ve vaginal akıntıda glukoz iesti bakılarak tohumlanan 283 dişi köpekte $\% 71$ gebelik elde edilmiş, gluko\% testinin. en uygun çiftleştirme zamanı açısından son derece tatmin edici ve uygulanabilir bir test olduğu sonucuna varılmuşır (17).

Bununla beraber. baž araşurmalarda bu metodun dişi kn̈peklerde östrusun saptanması uygulamalarmnda bir kısım köpeklercic hafï negatil reaksiyon gözlenirken djgerlerinde tam negaltif reaksiyon gözlenmesi (erkek köpeg̣in kabulünden sonraki zamana kadar) veya tüm östrus periyodu boyunca devaml olarak pozitif reaksiyon gözkenmesinden dolayı pratikte kullanılamayacăğ da bildirilmişlir $(1,30.11)$.

Evans ve Sutıon (9), vaginal akıntıda glukoz içeriğginin. çilileştirme zaman ve optimum fertilite için de ğcrli bir indikatör olduğgunu, östrus boyunca glukoz testi negatif sonuf verdiği sürede yapılan tohumlamalarda en iyi fertilitenin elde cdildiğini ve ikinci negatif glukoz reaksiyonundan önce çiflleşmeye izin verilmemesi gerektiğini vurgułamakıadı (9). Bununla birlikte, bazı köpeklerde negatif glukoz reaksiyonu varken diğerinde hafif pozitif reaksiyon göriinduğii, bazılarmela isc lün östrus periyodu boyunca reaksiyon gortiilmediğ de belirtilmektedir (15).

Bu çalışmada. vaginal sitoloji ile birlikłe vag̣inal sckret gluko\% içeriğinin tespil edilmessiyle. en uygum 10humlama zamanmm belirlenebilmesi re raginal sekiclin gluko\% içeriğgndeki değgşimlerin pratikle istrusun uspitinde kullanılabilirliğg araştırılımışır.

\section{Materyal ve Metot}

Bu çalışmada hayvan kliniğine suni lohumlama isteği ile getirilen, değişik nktan, herhangi bir reproduiktil hozukluğu olmayan 15 dişi köpck kullamılımışı. Materyal olarak kullanılan hayvanlarda yaş smorlaması yapılmanış ve dişiler aynı urktan erkekterden alman spermalar ile tohumlanmışır.

Östrus belirtileri gösterdiği ve lohumlama isteği ile kliniğe getirilen köpeklerin klinik muayeneleri yapularak. genel sağlık durumları ve özel olarak isc reproduiktil problemleri olup olmadığ belirlendi ve sağ lıklı olduğ karar verilenler çalışmaya alındı.

\section{Östrus davranışlarının saptannasıı}

Osıus davamb̧armmn tespiti için iki knter goł onüune alındı: Erkeğin ilgusisi ve dişinin erkeğg kabul durumu. Her iki kriter de (-), (+), (++) ve $(+++)$ ile değerlendirildi.

\section{Klinik östrus bulguları}

Östrusun klinik beldeklerinden. vulva äklenil ve vaginal akınts kriterleri değerlendirilds. Vulva ödemi (-). $(+) .(++)$ ve $(+++)$ olarak, vaginal akınt ise vagina akmusinun renginin lespiti olarak degerlendirildi. Ayruca. anamnezle belirtilen proöstrus kanamasmm haşlaṇı̣ tarihine göre östrus güü̈ saptandı. Ilk klinik kon:rollerde tohumlanmasi uygun olmadigna karar verilen disiler kli-

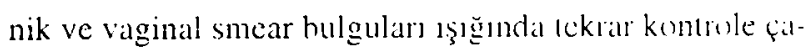
gririldi.

\section{Vaginal smear yöniinden değerlendirme}

Uygun şekilde tespit edilen dişilerin vag̣inasinnn dorsal duvarmdan colton swap ile alman ömeklerden lam ii\%erine yaylarak hazırlanan preparatlar Test-Simplets (Boehringer-Mannheim-Germany) yardmuly boyand ve Christiansen (2)'e göre en a\% 100 epilel huicussi sayllarak saptanan histolojik indekslere göre değerlendurildi.

\section{Vaginal içeriğin glukoz miktarının belirlenmesi}

Glukoz içeriğinin belirlenmesi için steril bir pens ile tutulan gluko\% test çubuğu (Bochringur-MannhcimGermany) spekülüm ile açılnuş olan voulvadan içeri yö̆nlendirildi ve 1 dakikadan az olmamak izcre heklctilip dşarı alındı. Glukor tesı çubuğunda meydana gelen renk 
değişikliğj renk skalasından okunarak glukoz miktarı ("). $(+) .(++),(+++)$ ve $(++++)$ ile derecelendirildi. Dişi $k \ddot{j}-$ peğin her klinik muajenesinde vaginal akınlıda gluko\% içeriğ lespil edildi.

Klinik ve vaginal smear bulgularma göre östrusta olduğ saptananlar tohumland. Östrusta olmayanlar ise uygưn sïrclerde tckrar kontrola çağırıldı.

\section{Tohumlama}

Dişiler anammezle belirlenen proöstrus kanaması. ostrusun klinik bulgulan. çifleşme davranışarı ve vaginal smear indeksi bulgulan gö\% önüne alınarak: aynı ırk erkeklen aluman ve en a\% \%70 motilite özelliği gösteren spermalarla ve 9-13. günler arasmda toplam iki kez tohumland. Tohumlamalar plastik uterus kateterleri ile vaginal olarak yapıldi. Gebelik. 30. günden sonra yapılan ultrason tetkiki ve doğum sonuçlan almarak tespit edildi.

Pozitil ve negatif glukoz test sonuçlarma göre elde edilen gebelik oranları arasındaki farkm önem konırolii student-T iesı yöntemi kullanılarak saptandı.

\section{Bulgular}

Östrus davramışlam, iostrusun klinik hulg̣ulant. vat ginal snear bulguları ve vagginal akmudal glukor içeriğgne bakılarak tohumlanan 15 köpekte clde cdilen veriler loplu halde Tablo l-4'te verilmiştir. Vag̣nal smeatr onneğ alunması, hazırlanması ve vaginal akınuda gluko\% varlığmm saptanması yöntemleri Şekil 1 ve 2'de: glukor lesti poritil ve negatif sontiç alınan köpeklerin ohumlanmlalarmedaun clde edilen ve 1. ve 2. Tohumlamalammal gore deger lendirilen gebelik oranlar da Tablo 5 ve 6 da göskrilmos tir.

llk klinik muayenede vaginal akuлtuda gluku\% varlıg (+) olarak saptanan 3. 8, 12 ve 1.3 no'lu köpcklerde glu koz varlığ ikinci ya da üçiincii klinik konırolda (-): 2 ve 9 no'lu köpeklerde $(++)$ olan gluko\% varlyğ $(+)$ olarak hulunurken 1.4, 5, 6.7. 10.11. 14 ve 15 milu kijpcklerde ilk kontrolle ikinci ya da içüuncii kontrollerde gluko\% a alrlı̆̆ durumu değgişiklik göstermemiştir.

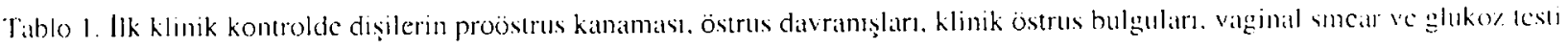
bulgularl.

Tithle 1. Procstrus hlecding. estrus behavior, clinical estrus evidence. vaginal smear and glucose lest in the lirst climical examumation.

\begin{tabular}{|c|c|c|c|c|c|c|c|}
\hline \multirow{2}{*}{$\begin{array}{c}\text { Halyan } \\
\text { nos }\end{array}$} & \multirow{2}{*}{$\begin{array}{l}\text { Proöstrus } \\
\text { (Giin) }\end{array}$} & \multicolumn{2}{|c|}{ Östrus dav ramıșları } & \multicolumn{2}{|c|}{ Klinik ostrus bulgulanl } & \multirow{2}{*}{ 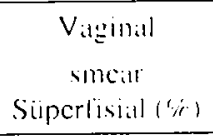 } & \multirow{2}{*}{$\begin{array}{l}\text { Gluko\% } \\
\text { cesti }\end{array}$} \\
\hline & & $\begin{array}{c}\text { Erkçgin } \\
\text { ilgisi }\end{array}$ & $\begin{array}{l}\text { Erke gi } \\
\text { kabul }\end{array}$ & $\begin{array}{l}\text { Vulvall } \\
\text { idem }\end{array}$ & $\begin{array}{c}\text { Vatginal } \\
\text { atimti }\end{array}$ & & \\
\hline 1 & 11. & +++ & +++ & +++ & Renksiz. & 90 & - \\
\hline 2 & 6. & ++ & - & ++ & Kanhi & 60 & ++ \\
\hline 3 & 9. & $+t$ & + & +++ & Pembc & $70)$ & + \\
\hline 4 & 6. & - & - & + & Kimlı & 1.3 & +++ \\
\hline 5 & 10 & +++ & +++ & +++ & Simain sartst & 90 & - \\
\hline 6 & 9 & $++t$ & - & $+t+$ & Saman sarms & 79) & + \\
\hline 7 & 12 & + & ++ & $+t+$ & Pconbe & 82 & \\
\hline 8 & 10. & - & + & +++ & Samiln sitlisl & 9() & + \\
\hline y & 3 & - & - & + & Kimlı & 32 & ++ \\
\hline 10 & 11. & $++t$ & + & +++ & Saminn sallisı & 83 & \\
\hline 11 & 6 & $++t$ & - & +++ & Samminn Satrisb & 74 & - \\
\hline 12 & 6 & + & - & ++ & $\mathrm{K}: \operatorname{lnl} \mathrm{l}$ & 60 & +++ \\
\hline 13 & 11. & $++t$ & + & +++ & Rcuksiz & 94 & + \\
\hline 14 & 9 & +++ & + & +++ & Reuksiz. & 97 & + \\
\hline 15 & 12 & +++ & - & +++ & Siamiall silltst & 92 & \\
\hline
\end{tabular}

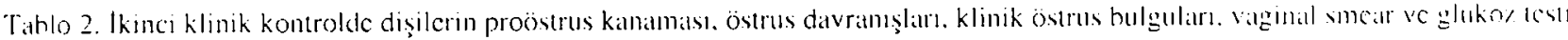
bulgular

Table 2. Proestur blecding, estrus behavior. clinical estrus cvidence. vaginal smear and glucose lest in the second clinicil cximminaturn.

\begin{tabular}{|c|c|c|c|c|c|c|c|}
\hline \multirow{2}{*}{$\begin{array}{c}\text { Hatyvan } \\
\text { no }\end{array}$} & \multirow{2}{*}{$\begin{array}{l}\text { Proöstrus } \\
\text { (Giiin) }\end{array}$} & \multicolumn{2}{|c|}{ Ostrus davranışlanı } & \multicolumn{2}{|c|}{ Klinik östrus hulguları } & \multirow{2}{*}{$\begin{array}{c}\text { Vitginal } \\
\text { sincilr } \\
\text { Suiperfistall }(\%)\end{array}$} & \multirow{2}{*}{$\begin{array}{l}\text { Ciluko\% } \\
\text { Icsti }\end{array}$} \\
\hline & & $\begin{array}{l}\text { Erkçูin } \\
\text { ilgisi }\end{array}$ & $\begin{array}{l}\text { Erkeği } \\
\text { kabul }\end{array}$ & $\begin{array}{l}\text { Vulval } \\
\text { ödem }\end{array}$ & $\begin{array}{l}\text { Viaginal } \\
\text { akmul }\end{array}$ & & \\
\hline 2 & 9 & +++ & - & ++ & Kilnlı & 75 & $+t$ \\
\hline 4 & 10. & + & ++ & ++ & Pembe & 90 & ++ \\
\hline 9 & 11. & ++ & - & $++t$ & Pembe & 62 & + \\
\hline 11 & 9 & $+t+$ & - & +++ & Sambin sillusi & 74 & - \\
\hline 12 & 9 & ++ & - & ++ & Killolı & 60 & ++++ \\
\hline
\end{tabular}



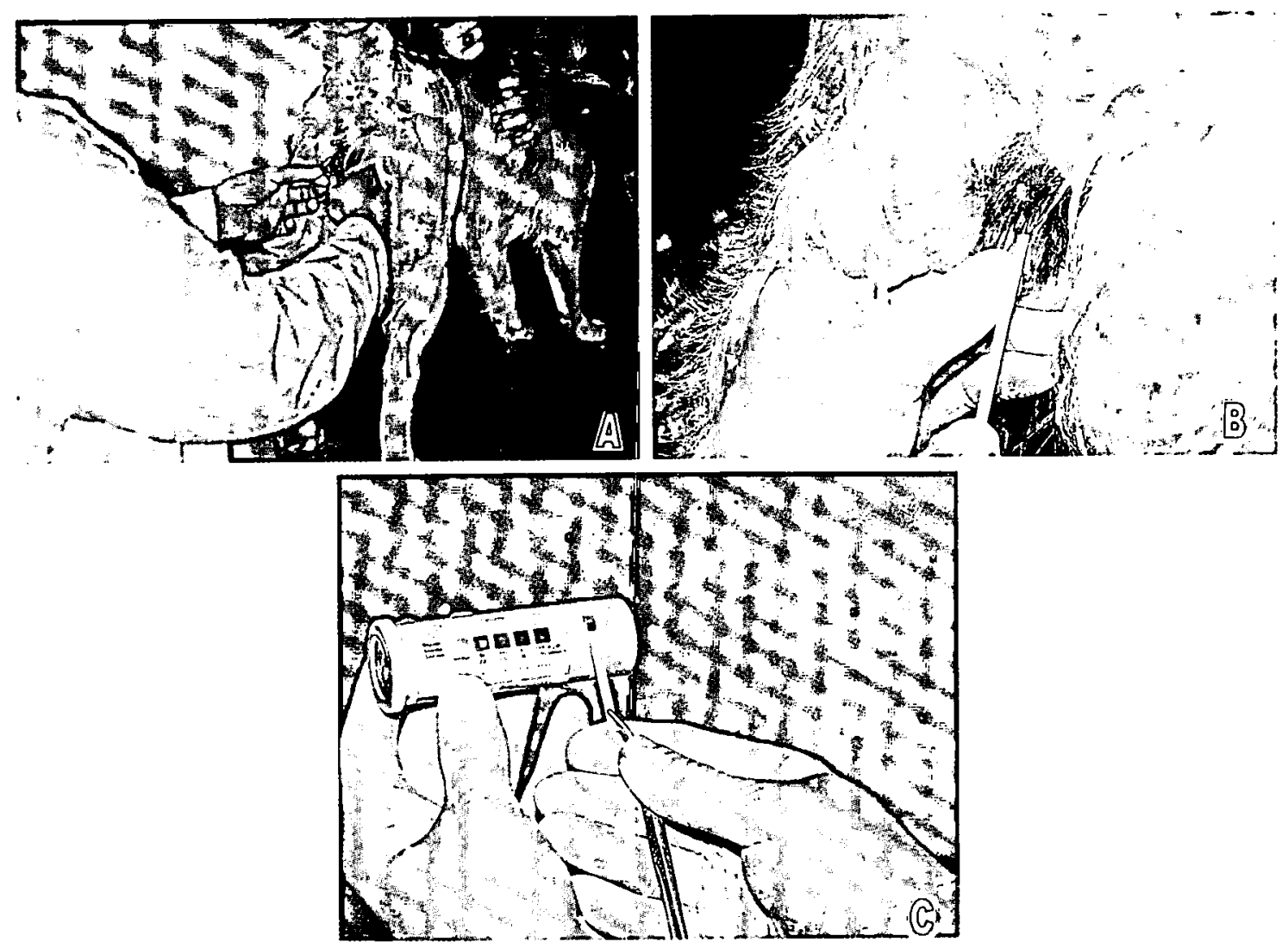

Şekil I. A. B ve C-Vatginat içeriğin glukoz miksarmm belirlenmesi

Figure I. A. B and C- Detection of glucosc in vaginal discharge.
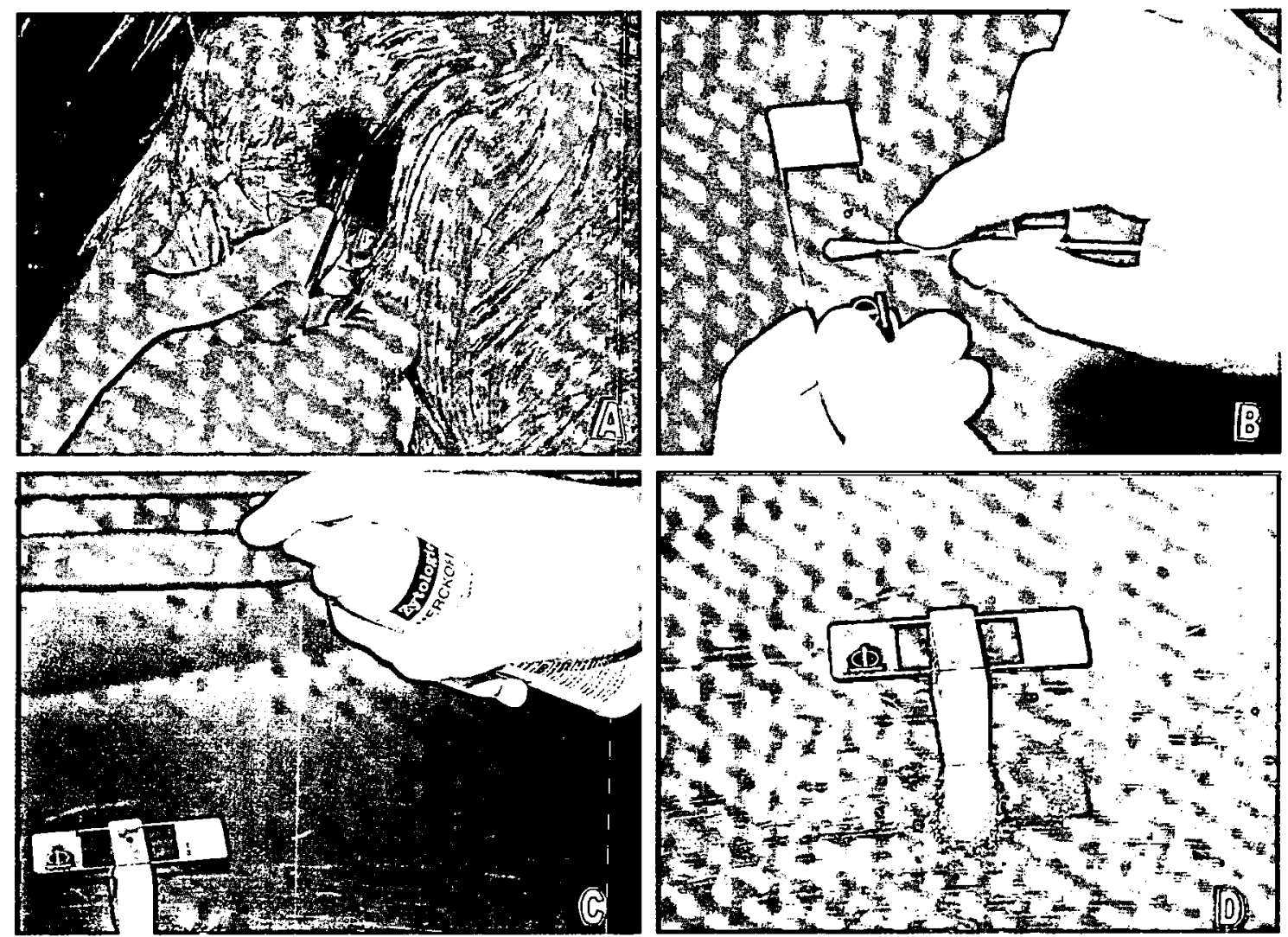

Şckil 2. A. Vatoinal smear önchlerinin alonması. B. C ve D- Preparatun hatarlanmalst.

Figurc 2. A- Tating of vaginal umear samples. B. C and D- Preparation of smear sample. 


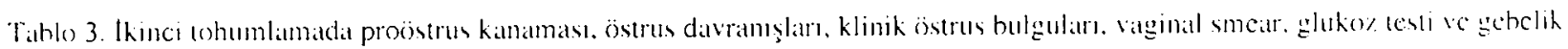

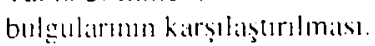

Table 3. Comparison of proestrus blecding. cetrus behavior. clinical estrus cidence. vaginal smear. glucose lest and pregulancy ralle in the sccond insemination.

\begin{tabular}{|c|c|c|c|c|c|c|c|c|}
\hline \multirow{2}{*}{$\begin{array}{c}\text { Hayvatn } \\
\text { no }\end{array}$} & \multirow{2}{*}{$\begin{array}{l}\text { Proöstrus } \\
\text { (Giin) }\end{array}$} & \multicolumn{2}{|c|}{ Östrus dilvramıșları } & \multicolumn{2}{|c|}{ Klinik östrus bulguları } & \multirow{2}{*}{$\begin{array}{c}\text { Valginal } \\
\text { smear } \\
\text { Superfisial (\%) }\end{array}$} & \multirow{2}{*}{$\begin{array}{l}\text { Gluko\% } \\
\text { lesti }\end{array}$} & \multirow[b]{2}{*}{ Gichelik } \\
\hline & & $\begin{array}{l}\text { Frkcgin } \\
\text { ilgisi }\end{array}$ & $\begin{array}{l}\text { Erkegi } \\
\text { kabul }\end{array}$ & $\begin{array}{l}\text { Vulval } \\
\text { ödem }\end{array}$ & $\begin{array}{c}\text { Vaginal } \\
\text { atimul }\end{array}$ & & & \\
\hline 1 & 13. & +++ & +++ & +++ & Renksir. & 96 & - & + \\
\hline 2 & 10. & +++ & + & $+t+$ & Samann sarrsis & 89 & + & - \\
\hline 3 & 12 & ++ & + & +++ & Samant silrus & 94 & - & + \\
\hline 4 & 10. & ++ & - & +++ & Samian silrusl & 93 & +++ & + \\
\hline 5 & 12. & $+t+$ & +++ & +++ & Sitlm:ans Sill's! & 96 & & + \\
\hline 6 & 12. & +++ & - & +++ & Salmall Sarısı & 97 & + & + \\
\hline 7 & 13 & + & ++ & $+t+$ & Pembe & 90 & & + \\
\hline 8 & 13 & - & + & trt & Salmann sarlsi & $1(x)$ & & \\
\hline ) & 13 & ++ & ++ & +++ & Pembc & 98 & + & - \\
\hline (1) & 13. & +++ & + & +++ & Salman sarms & 93 & & + \\
\hline 11 & 11. & +++ & ++ & +++ & Saman sarnsı & 89 & - & - \\
\hline 12 & 11. & ++ & ++ & +++ & Pembc & 98 & & - \\
\hline 1.3 & 13. & ++ & + & $++t$ & Renksiz & 95 & . & + \\
\hline 14 & 11. & +++ & + & +++ & Renksi\% & 94 & + & + \\
\hline 1.5 & 13 & +++ & - & +++ & Saman sarnsis & 94 & - & + \\
\hline
\end{tabular}

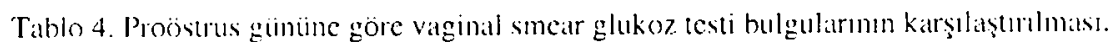

Table t. Comparison of vaginal smear and glucose test according to day of vaginal blecting.

\begin{tabular}{|c|c|c|c|}
\hline $\begin{array}{l}\text { Proöstrus } \\
\text { (giili) }\end{array}$ & $\begin{array}{l}\text { Ilaysan sayisi } \\
\text { (n) }\end{array}$ & $\begin{array}{c}\text { Suiperfisial hiicre } \\
\text { indeksi ontalimalsi }(\%)\end{array}$ & $\begin{array}{l}\text { (jlukos pozitif lest } \\
\text { orlalimalsi (\%) }\end{array}$ \\
\hline 3. & 1 & 32.0 & $10(1) .0$ \\
\hline 6. & 4 & 71.0 & 75.0 \\
\hline 9 & 6 & 75.83 & 83.33 \\
\hline 10. & 5 & 90.4 & 8() .0 \\
\hline 11. & 7 & 88.85 & 42.85 \\
\hline 12 & 4 & 94.75 & 50.0 \\
\hline 13. & 7 & 95.14 & 14.28 \\
\hline
\end{tabular}

Tablo 5. Ilk cohumlammada pozitil ve negatit glukor test sonuçlarr.

Tathle 5. Positive and nesative glucose test results in first inseminations.

\begin{tabular}{|c|c|c|c|c|}
\hline Gluko\% test & Hilyvan salyısı & $(\%)$ & Gebe hayvan salyos & $(\%)$ \\
\hline Pozitif glukozlest & 9 & 60 & 5 & 5.5 .55 \\
\hline Negatif gluko\% lest & 6 & 40 & 5 & $83.33^{\circ}$ \\
\hline
\end{tabular}

Tablo 6. Ikinci tohumlamiadia poritil "'s negatif glukoz test somuçlarn

Tabic 6. Positive and nesative glucose test results in second inseminations.

\begin{tabular}{|c|c|c|c|c|}
\hline Glukom test & Hayyaill sayııs & $\left(C^{\prime}\right)$ & Gebe hayvaln salym & $(\%)$ \\
\hline Poritif gluko\% lest & 5 & 33.33 & 3 & $60,0 \%$ \\
\hline Vegatif glukoz test & 10 & 66.66 & 7 & 70.0 \\
\hline
\end{tabular}

$\because p>0.015$

\section{Tartışma ve Sonuç}

Köpeklerde en uygun tohumlama zamanmm belirlenmesinde bir çok laktör genellikle bir arada değerlendirilerck sonuca gidlilmektedir. En uygun tohumlama \%amanımı belirlenmesi gerek doğal çifleştirme ve gerekse sun'i tohumlamı açısından ö\%cllikle de dondurulmuş sperma kullanmmunda köpeklerde kabul cdilchilir licrilite sonuçları açısından son derece önemlidir.

Vaginal akmudaki glukos varlgğun en uygun w humlama zamammm belirlenmesinde kullamlahilir hir in-

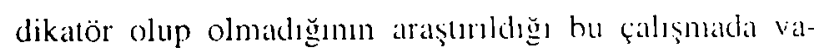
ginal smear bulguları da değerlendirimişir. Bu muatyenc 
ve degerlendirmelerde suiperfisiyal huicre indeksleri pro-

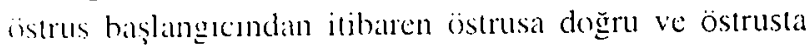
arıs grislerirken. vaginal akıntuda glukoz varlığ da bazı guiuler için belirleyici olmasa da suiperfisiyal huicre indeksi ile nệallif bir ilişki içinde olmuşur. Benæer biçinde. diğgr östrus belirleme kriterlerinden crkeģin ilgisi, dişinin erkeği kabulü, vulva ödemi, vaginal akmunm rengi gibi kimileri de proöstrus haşlangııından östrusa doğru göisterdikleri değişimlerde vaginal akıntıda glukoz

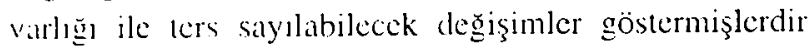
(Tiblo 1-3).

Elde edilen döl verimi sonuçları (\%70) açıssndan Valn der Holst ve Best (17)'in viginal smear muayeneleri, klinik ostrus beldekleri ve vaginal akıntıda gluko\% testi bakılarak tohumladłkları 28.3 dişi köpekten elde ettikleri \% 71 gebelik oramma çok yakm somuç elde edilmiş; saptanin gebelik oranları arassmdaki farkın istatistik degerlendirmesinde gruplar arası fark önenısiz bulunmasına karşı gluko\% testinin, en uygun çiflleştirme zamanı aç1sundan diğer verilerle hirlikı kullanıldığında tatmin edici ve uygulanabilirliği kolay bir lest olduğu sonucuna varılnuşur.

Gluko\% lest pozilif dişilerin tohumlanmasundan elde edilen gechelik oranlan ilk klinik kontrolde tahımlanan disilerde \%55.55: ikinci klinik kontrolde tohumlanan disilerde ise $\% 60.00$ olarak bulunmuş ve hu oranlar Van der Holst we Best (17)'in f̧alışmalarında 23 köpekien sadeec 2 sinde gebelik bildirilen sonuçtan yüksek elde edilniş̧lir. Burada en uygun lohumlama zamanının belirlenmesinde kritcr olarak bakılan klinik muayene kriterlerinin farkhlığ ve lohumlama sayı ve dozlarmun ctken olabilece g̣g dìșiniilmelidir

Vaginal akmutıda saptaman glukoz varlığınn ölfillmesinde raksiyonun hir pozitiften dört pozitife kadar değisiklik göslermesi diğer bir ifade ile reaksiyonun şiddeti. bu degerlerin kimi dişilerde hafif. kinilerinde ise belirgin olahilnesine bağgladır. Bu fallı̧mada da gözlendiği gibi hara dişilcrde lüm östrus boyunca devamlı pozitif reaksiyon izlencbilmekledir (1.10). Bu durum, vaginal akıntıda glıko\% varlığının en uygun tohumlama zamanınun belirlenmesinde pratikte tek başma bir indikatör olarak kullanılanlayaca ğ $(10,11,16)$ görüslerine de destek rermekıcdir. Ancak. clde edilen gehelik oranlan ile gös-

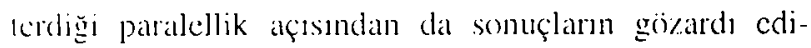
kemeyeceğg de göriilmektedir.

Sonuç olarak. bu çalışmada elde edilen bulgulara göre. köpeklerde uygun lohumlama zamammn belirlenmesinde rag̣inal içerikte glukoz varlı ğınm saptannası, elde edilecek gecbelik sonuçları (\%70) açısından bir indikatoir olarak kullanılibileceğgni göstermektedir. Ancak. leaksiyonun hal\%1 kïpeklerde halil negatif ve hazılarnda ise tiim ostrus boyuncal poyitif olmass nedeniyle en uygun lohumlama zamamm belirlenmesinde tek başına bir indikilor olarak kullanmmmn yeterli olamayacağ peklerin bircysel özelliklerinin de dikkatc almarak diğer muayene ve değgerlendirmeler ile birlikle kullanılmasmm

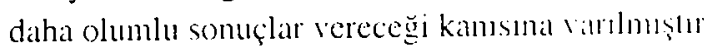

\section{Kaynaklar}

1. Andersen K (1977): Nordec sympestum an arluficial msemination in dogs and depplieesing of sement. Upposalas "Alummışur" Christiansen IbJ (1984): Reproshostuen in the Dog and Cat. Bailliere and Tindill. I. onden

2. Christiansen IB.J (1984): Reprodection in the Dor: and Cat. Bailliere and Tindill. London.

3. Concannon PW (1986): Canine Phreiolesey of Reproduction. 23-77. In: TJ Burke (Ed). Smoll Amimal Reproduction and Infertility. Lea and Febiger. Philadelphrit.

4. Concannon PW (1989): Physiologe of commi arcicu!

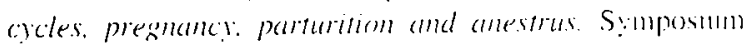
on Reproduction in the Dog. Octeber 5. 6. Copentilgen

5. Concannon PW, MCCann IP, Temple C (1989) Bioles. and Endocrinoles's of Oratution. Presinang and Par. Iurtion in the Do: J Reprod Fert. Suppl. 39. 325

6. Cupps TP (1991): Reproduction in Demestre Animals. Fo urih ed. Academic Presss lac. London.

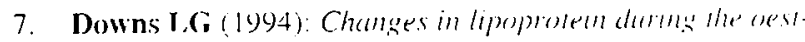
rus cycle of the bitch Res Val Sci. 56. 82-88

8. England GCW (1998): Allen's Fermlur and obstemies in

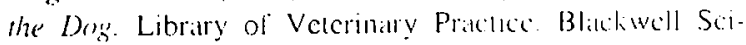
ence. Malden.

9. Evans JM, Sutton D)J (1989): The use of hormumes specially progestagens. to control oestras in biches J Rep Fert. Suppl, 39, 163-173.

10. Gill HP, Kaufman CF, Foote Rl', Kirk RW $(1970)$, sificial insemination of beagle biches with freshet collected. liquid-stored. and frosen stried sements. Am J Ver Res. 31. 1817-1813.

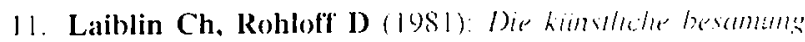

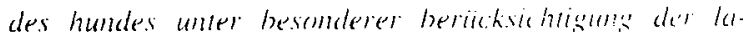
ufigkeilsdiagnose. Ticrarzll Prax.9. 237-244.

12. MoDonald LE (1989): Veterinary Endectimeles: Rep rodection. L_cil and Febiger. Philadelphiat.

13. Olson PN, Nett T.M (1989): Endecrin resulation of the

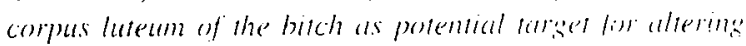
fertility. J Reprod Fert. Suppl. 39. 27-40

14. Phemister RI), Holst PA. Xspano JS. Hopwood MII.

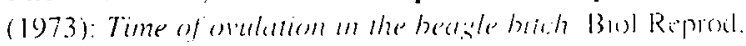
8. 74-82.

15. Selbmann M (1965): Dee Glekesefest im Zanthutsehret der Hundin zur Bestimumín de' Orwlation. Klom Prixis. 10. 58-59.

16. Shille VM (1977): Nordic simpessium on artuliciel in-

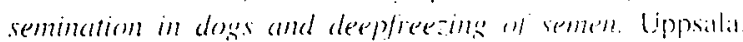

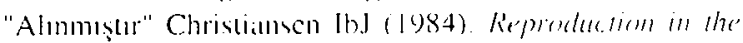
Dog and Cat. Baillicere and Tindial. I onding

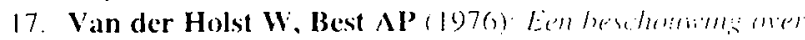

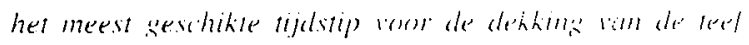
Tijdschr Dier:. 101. 658-603

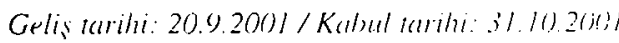

Yazışma adresi:

Des: Dr. Ali Daskm

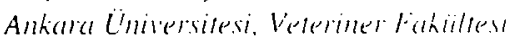

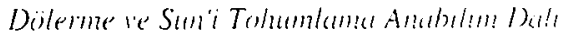

Ool/O Diskat) Ankeral

daskin (a) reterimareankara.edu.t) 